\title{
Produksi Metabolit Utama (-)-Citrinin, pada Kultur Jamur Endofit Penicillium sp dari Tanaman Teh
}

\author{
Production a Major Metabolite (-)-Citrinin in the Culture of the Endophytic Fungus \\ Penicillium sp from a Tea Plant
}

\author{
Andria Agusta* dan Yuliasri Jamal \\ Laboratorium Fitokimia, Bidang Botani, Puslit Biologi, LIPI, Jl. Raya Jakarta-Bogor Km 46 Cibinong 16119 \\ E-mail: bislunatin@yahoo.com *Penulis untuk korespondensi
}

\begin{abstract}
Endophytic fungi have been recognized as source of broad range biological active metabolites with high chemical structure diversity. The purpose of this research is to isolate and characterize major metabolite produce by the endophytic fungi Penicillium sp isolated from a tea plant. Cultivation of endophytic fungus Penicillium sp (AB2245443) in liquid medium PDB on a rotary shaker at $100 \mathrm{rpm}$, temperature 25 $30^{\circ} \mathrm{C}$ for 7 days, produced a yellow metabolite. Separation of metabolite through chromatography technique and followed by chemical structure elucidation based on MS, IR, NMR spectra and published data showed that the yellow metabolite is (-)citrinin.
\end{abstract}

Key words: tea plant, Camellia sinensis, endophytic fungus, Penicillium sp, (-)-citrinin

Diterima: 22 Januari 2008, disetujui: 20 September 2008

\section{Pendahuluan}

Mikroba endofit adalah salah satu
golongan mikroba di alam yang hidup
berasosiasi dengan tumbuhan tanpa
menimbulkan efek merugikan bagi
tumbuhannya (Bacon dan White, 2000).
Mikroba endofit, terutama jamur endofit,
merupakan sumber yang kaya akan metabolit
sekunder bioaktif (Tan dan Zou, 2001; Zhang
et al., 2006), sehingga Owen dan Hundley
(2004) menyebutnya sebagai the chemical
synthesizer inside plant.

Dalam kurun waktu sepuluh tahun belakangan, berbagai jenis jamur endofit telah dilaporkan dapat memproduksi berbagai jenis metabolit sekunder dengan aktivitas biologi yang beragam. Horn et al., (1995) melaporkan mengisolasi fomopsikalasin dari kultur jamur endofit Phomopsis sp yang berasosiasi dengan tumbuhan Salix gracilostyla var. melanostachys. Metabolit ini secara in-vitro memperlihatkan aktivitas biologi sebagai antibakteri melawan Bacillus subtilis, Staphylococcus aureus dan Salmonella gallinarum, di samping juga aktif sebagai antijamur melawan Candida albicans. Dari kultur jamur endofit Cryptosporiopsis cf. quercina yang berasosiasi dengan tumbuhan Tripterigium wilfordii juga telah dilaporkan keberadaan suatu analog asam tetramat, kriptosin yang bersifat sebagai antimikotik yang potensial melawan Pyricularia oryzae (Li et al., 2000).

Tahun 1996, Krohn et al., melaporkan isolasi dan karakterisasi tiga metabolit fenolik dari kultur jamur endofit Phomopsis sp yang berasosiasi dengan tumbuhan Teucrium scorodonia (Lamiaceae), yaitu fomopsin A dan C memperlihatkan aktivitas sebagai antibakteri melawan Bacillus megaterium. Di pihak lain, Pestalotiopsis microspora yang berasosiasi dengan tumbuhan Terminalia morobensis menghasilkan pestasin dan isopestasin yang aktif sebagai antibakteri dan antioksidan. Brady et al., (2000) melaporkan isolasi karakterisasi 
turunan senyawa fenolik, sitosporon D dan E dari jamur endofit Cytospora sp CR 200 dan Diaporthe sp CR 146 yang memperlihatkan aktivitas biologi sebagai antibakteri yang potensial melawan $S$. aureus, Enterococcus faecalis, E. coli dan juga terhadap jamur Candida albicans. Hal yang lebih menarik, kedua metabolit ini juga aktif melawan bakteri yang telah resisten terhadap antibiotik yang beredar di pasar global saat ini.

Jamur marga Penicillium merupakan salah satu kelompok jamur yang kosmopolit dan umum ditemukan di berbagai habitat (Samson et al., 1995). Pada tumbuhan tingkat tinggi, umumnya jamur dari marga Penicillium bersifat saprofit dan/atau bersifat parasit. Namun beberapa jenis jamur Penicillium juga telah dilaporkan sebagai endofit yang berasosiasi dengan beberapa tumbuhan tinggi, seperti $P$. janthinellum dari tumbuhan Melia azedarach (Marinho et al., 2005), Penicillium sp dari tumbuhan Taxus brevifolia (Stierle et al., 1999).

Salah satu jamur endofit yang diisolasi dari tanaman teh juga diidentifikasi sebagai Penicillium sp (AB2245443; Agusta et al., 2006). Jamur endofit ini jika ditumbuhkan di atas medium agar miring (PDA) akan mensekresikan suatu metabolit yang memiliki sifat berfluoresensi jika dipaparkan dengan sinar UV $365 \mathrm{~nm}$. Untuk itu, pada tulisan ini akan dilaporkan kultivasi jamur endofit pada berbagai medium tumbuh, isolasi dan karakterisasi metabolit utama dengan sifat berfluoresensi pada kultur jamur endofit tersebut.

\section{Metode Penelitian}

\section{Skrining produksi metabolit sekunder}

Untuk skirining metabolit sekunder yang diproduksi oleh jamur endofit Penicillium sp digunakan 5 jenis medium semi sintetik dengan komposisi seperti terlihat pada Tabel 1. Selanjutnya jamur endofit Penicillium sp di tumbuhan di dalam Erlenmeyer ukuran $100 \mathrm{ml}$ yang berisikan $30 \mathrm{ml}$ untuk setiap jenis medium pada suhu ruang $\left(25-33^{\circ} \mathrm{C}\right)$ dengan kecepatan agitasi 90 rpm. Produksi metabolit sekunder dimonitor setiap 24 jam dengan cara melakukan sampling $5 \mathrm{ml}$ medium tumbuh, lalu diekstraksi dengan etilasetat dan dianalisis dengan $\mathrm{KLT}\left(\mathrm{SiO}_{2} \mathrm{GF} 254, \mathrm{CHCl}_{3}: \mathrm{MeOH}=\right.$ 5:1) dengan penampak noda $5 \%$ vanillin $/ 10 \%$ $\mathrm{H}_{2} \mathrm{SO}_{4}$. Atau dengan cara memaparkan sinar UV $365 \mathrm{~nm}$ ke medium tumbuh.

\section{Produksi dan isolasi metabolit utama}

Jamur endofit Penicillium sp ditumbuhkan di dalam 5 buah Erlenmeyer ukuran $500 \mathrm{ml}$ yang berisikan $200 \mathrm{ml}$ medium cair potato dextrose broth (PDB) dengan kecepatan agitasi $100 \mathrm{rpm}$ pada suhu ruang $\left(25-33^{\circ} \mathrm{C}\right)$. Setelah 7 hari, seluruh medium tumbuh berikut biomass diekstraksi dengan etil asetat dan selanjutnya dipekatkan dengan penguap putar sehingga diperoleh $495 \mathrm{mg}$ ekstrak etil asetat. Ekstrak kasar yang diperoleh tersebut selanjutnya dipisahkan dengan metoda kolom kromatografi yang menggunakan silika gel sebagai fasa diam dan $\mathrm{CHCl}_{3}-\mathrm{MeOH}$ (4:1) sebagai fasa bergerak sehingga diperoleh 68.3 mg produk metabolit sekunder berupa serbuk berwarna kuning.

\section{Karakterisasi metabolit utama}

Struktur kimia metabolit utama ditentukan berdasarkan sifat karakter fisikokimianya yang dilakukan dengan batuan peralatan sebagai berikut. Rotasi optik diukur dengan alat polarimeter digital (Jasco DIP-360) dengan konsentrasi $1.1 \mathrm{mg} / \mathrm{ml}$ di dalam etanol pada temperatur $24^{\circ} \mathrm{C}$ dan panjang sel $50 \mathrm{~mm}$. FAB-MS diukur dengan menggunakan alat spektrometer masa JMS SX-102 A. Spektrum IR diukur dengan alat spektrofotometer Shimadzu FT-IR 8500 dengan plat $\mathrm{KBr}$. Sedangkan spektrum ${ }^{1} \mathrm{H}$ - dan ${ }^{13} \mathrm{C}$-RMI diukur dengan spektrometer JEOL JNM-Lambda 500 yang dioperasikan pada $500 \mathrm{MHz}$ untuk ${ }^{1} \mathrm{H}$ dan $125 \mathrm{MHz}$ untuk ${ }^{13} \mathrm{C}$ di dalam pelarut $\mathrm{CDCl}_{3}$. Geseran kimia diberikan dalam skala $\delta$ (ppm) yang relatif terhadap tetrametilsilana (TMS, $\delta=$ 0 ) sebagai internal standar, dan konstanta kopling diberikan dalam satuan Herzt.

\section{Hasil dan Pembahasan}

Hasil skrining tes memperlihatkan bahwa medium tumbuh PDB dari jamur endofit 
Penicillium sp memiliki karakteristik memancarkan sinar fluorisensi yang kuat jika diekspos dengan sinar UV pada panjang gelombang $365 \mathrm{~nm}$ setelah diinkubasi pada suhu ruang $\left(25-33^{\circ} \mathrm{C}\right)$ selama beberapa hari, dan efek ini tidak terlihat pada medium tumbuh lainnya. Begitu juga dengan hasil analisis KLT memperlihatkan bahwa kultivasi Penicillium sp di dalam PDB memperlihatkan adanya produksi satu metabolit sekunder utama.

Kultivasi jamur endofit ini secara lebih intensif memperlihatkan bahwa sifat berfluorisensi dari medium tumbuh muncul setelah diinkubasi selama 3 hari, dan semakin kuat sejalan dengan perpanjangan waktu inkubasi. Hal tersebut di atas merupakan indikator visual terhadap keberadaan dari metabolit sekunder dengan sifat fluorisensi yang kuat yang diproduksi oleh jamur endofit.

\section{Penicillium sp}

Ekstraksi medium tumbuh berikut biomassa dari jamur endofit Penicillium sp setelah ditumbuhkan di dalam PDB selama 7 hari dengan etil asetat, dan kemudian dipekatkan dengan penguap putar. Pemisahan ekstrak terlarut dalam etil asetat tersebut dengan kolom silika gel $\left(\mathrm{SiO}_{2}, \mathrm{CHCl}_{3}: \mathrm{MeOH}=\right.$ 4:1) menghasilkan $68.3 \mathrm{mg}$ serbuk berwarna kuning dengan nilai putaran optik $\left([\alpha]_{\mathrm{D}}\right)-25.5^{\circ}$ $\left(c=0.11,28^{\circ} \mathrm{C}, \mathrm{EtOH}\right)$.

Tabel 1. Komposisi medium tumbuh untuk skrining produksi metabolit sekunder.

\begin{tabular}{llrllr}
\hline \hline \multicolumn{1}{c}{ Medium } & \multicolumn{1}{c}{ Komposisi } & \multicolumn{2}{c}{ Medium } & \multicolumn{2}{c}{ Komposisi } \\
\hline \hline MY20 & Pepton & $5.0 \mathrm{~g}$ & Nutrient broth dengan & Pepton & $5.0 \mathrm{~g}$ \\
& Ekstrak yeast & $3.0 \mathrm{~g}$ & $5 \% \mathrm{NaC1}$ & Ekstrak beef & $3.0 \mathrm{~g}$ \\
& Ekstrak malt & $3.0 \mathrm{~g}$ & & $\mathrm{NaC1}$ & $5.0 \mathrm{~g}$ \\
& Glukosa & $200.0 \mathrm{~g}$ & & Air PAM & $1000 \mathrm{ml}$ \\
\multirow{5}{*}{ Triptik glukosa } & Air PAM & $1000 \mathrm{ml}$ & & & \\
& Tryptic soy broth & $30.0 \mathrm{~g}$ & $\mathrm{GYP}$ & Glukosa & $20.0 \mathrm{~g}$ \\
& Ekstrak yeast & $3.0 \mathrm{~g}$ & & Ekstrak yeast & $1.0 \mathrm{~g}$ \\
& Glukosa & $5.0 \mathrm{~g}$ & & Pepton & $5.0 \mathrm{~g}$ \\
& Air PAM & $1000 \mathrm{ml}$ & $\mathrm{K}_{2} \mathrm{HPO}_{4}$ & $0.5 \mathrm{~g}$ \\
PDB & & & $\mathrm{Mg}_{2} \mathrm{SO}_{4} \cdot 7 \mathrm{H}_{2} \mathrm{O}$ & $0.5 \mathrm{~g}$ \\
& & $4.0 \mathrm{~g}$ & & $\mathrm{FeSO}_{4} \cdot 7 \mathrm{H}_{2} \mathrm{O}$ & $0.01 \mathrm{~g}$ \\
& Potato strach & $20.0 \mathrm{~g}$ & & $\mathrm{CaCO}_{3}$ & $1.0 \mathrm{~g}$ \\
& Dekstrosa & $1000 \mathrm{ml}$ & & Air PAM & $1000 \mathrm{ml}$ \\
\hline \hline
\end{tabular}

Tabel 2. ${ }^{1} \mathrm{H}$ - dan ${ }^{13} \mathrm{C}$-RMI Citrinin dari kultur Penicillium sp.

\begin{tabular}{|c|c|c|c|c|}
\hline \multirow[b]{2}{*}{ Atom } & \multicolumn{2}{|c|}{ Citrinin dari kultur Penicillium sp } & \multicolumn{2}{|r|}{ Citrinin } \\
\hline & ${ }^{13} \mathrm{C}-\mathrm{RMI}$ & ${ }^{1} \mathrm{H}-\mathrm{RMI}$ & ${ }^{13} \mathrm{C}^{-\mathrm{RMI}^{*}}$ & ${ }^{1}$ H-RMI** \\
\hline C1 & 162.7 & $8.24(1 \mathrm{H}, \mathrm{s})$ & 162.9 & $8.25(1 \mathrm{H}, \mathrm{s})$ \\
\hline C3 & 81.6 & $4.78(1 \mathrm{H}, \mathrm{q}, \mathrm{J}=6.7 \mathrm{~Hz})$ & 81.8 & $4.80(1 \mathrm{H}, \mathrm{q}, \mathrm{J}=6.7 \mathrm{~Hz})$ \\
\hline $\mathrm{C} 4$ & 34.6 & $2.98(1 \mathrm{H}, \mathrm{q}, \mathrm{J}=7.1 \mathrm{~Hz})$ & 34.7 & $2.98(1 \mathrm{H}, \mathrm{q}, \mathrm{J}=7.1 \mathrm{~Hz})$ \\
\hline C4a & 139.0 & & 139.2 & \\
\hline C5 & 123.1 & & 123.2 & \\
\hline C6 & 183.8 & & 183.9 & \\
\hline C7 & 100.3 & & 100.4 & \\
\hline C8 & 177.2 & & 177.3 & \\
\hline C8a & 107.4 & & 107.5 & \\
\hline C9 & 18.2 & $1.35(3 \mathrm{H}, \mathrm{d}, \mathrm{J}=6.7 \mathrm{~Hz})$ & 18.2 & $1.35(3 \mathrm{H}, \mathrm{d}, \mathrm{J}=6.7 \mathrm{~Hz})$ \\
\hline C10 & 9.4 & $1.23(3 \mathrm{H}, \mathrm{d}, \mathrm{J}=7.1 \mathrm{~Hz})$ & 9.6 & $1.23(3 \mathrm{H}, \mathrm{d}, \mathrm{J}=7.1 \mathrm{~Hz})$ \\
\hline C11 & 18.5 & $2.02(3 \mathrm{H}, \mathrm{s})$ & 18.4 & $2.02(3 \mathrm{H}, \mathrm{s})$ \\
\hline C12 & 174.6 & & 174.7 & \\
\hline $\mathrm{OH}$ & & $15.11(1 \mathrm{H}, \mathrm{s})$ & & $15.13(1 \mathrm{H}, \mathrm{s})$ \\
\hline $\mathrm{OH}$ & & $15.87(1 \mathrm{H}, \mathrm{s})$ & & $15.90(1 \mathrm{H}, \mathrm{s})$ \\
\hline
\end{tabular}

*Hajjaj et al., 1999 ** Marinho et al., 2005 
Spektrum massa (FAB-MS) metabolit sekunder dari jamur endofit Penicillium sp ini memperlihatkan ion molekul $[\mathrm{M}+\mathrm{H}]^{+}$pada $\mathrm{m} / \mathrm{z}$ 251 yang mengindikasikan rumus molekul $\mathrm{C}_{13} \mathrm{H}_{13} \mathrm{O}_{5}$. Spektrum IR memperlihatkan serapan gugus karboksilat pada $3550-3100 \mathrm{~cm}^{-1}$. Interpretasi spektrum ${ }^{1} \mathrm{H}$-RMI (dalam $\mathrm{CDCl}_{3}$ ) dan spektrum ${ }^{13} \mathrm{C}$-RMI memperlihatkan adanya sebuah sinyal proton olefinik terisolasi pada geseran kimia $(\delta)$ 8,24 (1-H), dua sinyal proton metin kuartet pada $\delta 2,98(\mathrm{~J}=7,1 \mathrm{~Hz}, 4-\mathrm{H})$ dan $\delta 4,78(\mathrm{~J}=6,7 \mathrm{~Hz}, 3-\mathrm{H})$, dua metil doubled pada $\delta 1,23$ (4-CH3) dan $\delta 1,35$ (3-CH3) serta satu sinyal metil terisolasi pada $\delta 2,02(5-\mathrm{H})$ (Tabel 2). Di samping itu, dua sinyal karakteristik untuk gugus hiroksi yang membentuk kelat pada $\delta 15,11$ dan $\delta 15,87$ juga terdeteksi pada spektrum ${ }^{1}$ H-RMI-nya. Spektrum DEPT memperlihatkan bahwa metabolit sekunder dari Penicillium sp ini terdiri dari 13 buah atom karbon dengan 4 buah karbon kuaterner pada $\delta$ 100,3 (7-C), 107,3 (8a-C), 123 (5-C) dan 139,0 (4a-C) serta dua karbon karbonil pada $\delta 177,2$ (7-COOH) dan pada $\delta$ 183,8 (6-C). Data spektroskopi massa RMI metabolit dari kultur jamur endofit Penicillium sp di atas identik dengan (-)-citrinin (Hajjaj et al., 1999; Marinho et al., 2005).
(-)-Citrinin (Gambar 1) pertama kali diisolasi dari kultur Penicillium citrinum (Hetherington dan Raistrick, 1931) yang belakangan ditemui pada kultur lebih dari selusin jenis Penicillium, beberapa jenis Aspergillus (Bennett dan Klich, 2003) dan juga pada kultur beberapa jenis Monascus (Hajjaj et al., 1999). Baru-baru ini (-)-citrinin dilaporkan juga diproduksi oleh jamur endofit Penicillium janthinellum yang diisolasi dari buah Melia azedarach (Marinho et al., 2005). Di samping itu, Marinho et al., (2005) juga melaporkan bahwa citrinin memperlihatkan aktivitas biologi menghambat pertumbuhan bakteri Pseudomonas aeruginosa dan Bacillus subtilis, namun tidak aktif sama sekali terhadap Eschericia coli. Sedangkan pertumbuhan Leishmania Mexicana, citrinin dihambat secara total dalam waktu 48 jam pada konsentrasi 40 $\mu \mathrm{g} / \mathrm{ml}$. Di lain pihak, citrinin dikenal sebagai salah satu mikotoksin yang mengakibatkan efek nefrotoksik pada manusia dan hewan (Fink-Gremmels, 1999). Baru-baru ini juga dilaporkan bahwa citrinin dapat mengakibatkan efek penekanan sistem imun yang berakibat peningkatan kapasitas infeksi sel oleh parasit Toxoplasma gondii (Herzog-Soares dan Freire, 2004).

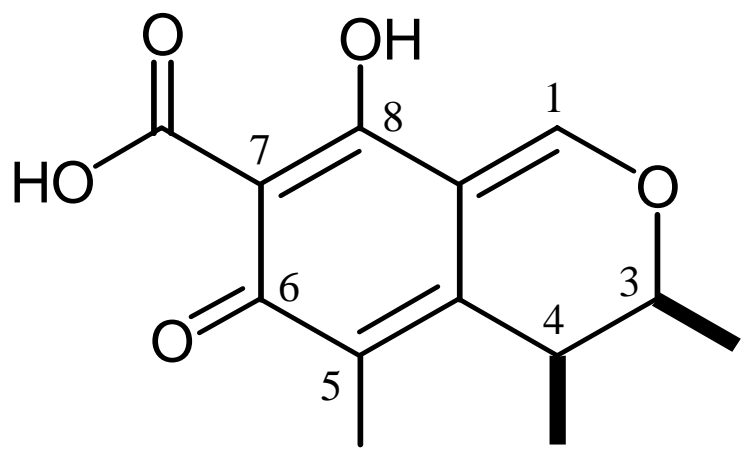

Gambar 1. Struktur kimia (-)-citrinin

\section{Kesimpulan}

Dari penelitian ini dapat disimpulkan bahwa (-)-citrinin adalah metabolit utama yang dihasilkan oleh jamur endofit Penicillium sp yang diisolasi dari tanaman teh pada medium cair PDB.

\section{Ucapan Terima Kasih}

Diucapkan terima kasih kepada Prof. Dr. Hirotaka Shibuya, Natural Product Chemistry Laboratory, Faculty of Pharmacy and Pharmaceutical Sciences, Fukuyama University, Fukuyama, Hiroshima, Japan atas pengukuran data spektroskopi RMI dan FAB-MS. 


\section{Daftar Pustaka}

Agusta, A., Ohashi, K. and Shibuya, H. 2006. Composition of the endophytic filamentous fungi isolated from tea plant Camellia sinensis. J. Nat. Med. 60 (3): 268-272.

Bacon, C.W. and White, J.F. 2000. Microbial Endophytes. Marcel Dekker, NY.

Bennett, J.W. and Klich, M. 2003. Mycotoxins, Clin. Microbiol. Rev. 16 (3): 497-516.

Brady, S.F., Singh, M.P., Janso, J.E. and Clardy, J. 2000. Guanacastepene, a fungal-derived diterpene antibiotic with a new carbon skeleton. J. Am. Chem. Soc. 122: 2116-2117.

Fink, G. 1999. Mycotoxin: their implications for human and animal health. Vet. Q. J. 21: 115-120.

Hajjaj, H., Klaebe, A., Loret, M.O., Goma, G., Blanc, P.J. and Francois, J. 1999. Biosynthetic pathway of citrinin in the filamentous fungus Monascus rubber as revealed by ${ }^{13} \mathrm{C}$ Nuclear Magnetic Resonance. Appl. Environ. Microbiol. 65 (1): 311-314.

Herzog-Soares, J.D.A. and Freire, R.B. 2004. Effect citrinin and in association with aflatoxin $\mathrm{B}_{1}$ on the infectivity and proliferation of Toxoplasma gondii in vitro. Br. J. Infectious Diseases 8 (1): 101-108.

Hetherington, A.C. and Raistrick, H. 1931, Studies in the biochemistry of microorganisms. Part XIV. On the production and chemical constitution of a new yellow colouring matter, citrinin, produce from glucose by Penicillium citrinum Thom. Phil. Trans. R. Soc. London Ser. B, 220B: 269-295.

Horn, W.S., Simmonds, S.J., Schwartz, R.E. and Blaney, W.M. 1995. Phomopsichalasin, a novel antimicrobial agent from an endophytic Phomopsis sp. Tetrahedron 51: 3969-3978.
Li, J.Y., Strobel, G.A., Harper, J., Lobkovsky, E. and Clardy, J. 2000. Cryptocin, a potent tetramic acid antimycotic from the endophytic fungus Cryptosporiopsis cf. quercina. Org. Lett. 23: 767-770.

Krohn, K., Michel, A., Bahramsari, R., Florke, U., Aust, H.J., Draeger, S., Schulz, B. and Wray, V. 1996. Biologically active metabolites from fungi 7; Aposphaerin A dan B two new chroman-4-ones from Aposphaeria sp. Nat. Prod. Lett. 8: 43-48.

Marinho, A.M.do R., Rodrigues-Filho, E., Moitinho, M. da L.R. and Santos, L.S. 2005. Biological active polyketides produce by Penicillium janthinellum isolated as an endophytic fungus from fruits of Melia azedarach. J. Braz. Chem. Soc. 16 (2): 280-283.

Owen, N.L. and Hundley, N. 2004. Endophytes the chemical sintesizer inside plants. Science Progress 87: 79-99.

Samson, R.A., Hoekstra, E.S., Frisvad, J.C. and Filtenborg, O. 1995. Introduction to food borne fungi. $4^{\text {th }}$ ed. Netherlands: Ponsen \& Looyen.

Stierle, D.B., Stierle, A.A. and Ganser, B.K. 1999. Isolation of two highly methylated polyketide derivatives from a yew-associated Penicillium species. J. Nat. Prod. 62: 1147-1150.

Tan, R.X. and Zou, W.X. 2001. Endophytes: A rich source of functional metabolites. Nat. Prod. Rep. 18: 448-459.

Zhang, Y., Li, X.M., Wang, C.Y. and Wang, B.G. 2006. A new naphthoquinonemine derivative from the marine algal-derived andophytic fungus Aspergillus niger EN-13. Chinese Chem. Lett., 18: 951-953. 